\title{
Kebutuhan Pengguna dalam Perancangan Disain Antarmuka SIMRS RSU ‘Aisyiyah Ponorogo
}

\author{
Rawi Miharti ${ }^{1}$, Dyan Riska Rohmasari ${ }^{2}$ \\ Akademi Kebidanan Yogyakarta ${ }^{1,2}$ \\ r4wimiharti@gmail.com¹, r.rahmadyan04@gmail.com²
}

\begin{abstract}
ABSTRAK
Latar Belakang: Salah satu elemen terpenting dalam membangun sebuah sistem informasi terkait kebutuhan pengguna adalah disain antarmuka sebagai gerbang penyalur informasi antara sistem dan penggunanya. RSU 'Aisyiyah Ponorogo telah menerapkan SIMRS, namun implementasinya belum menyeluruh. Pada bagian sensus harian rawat inap dan kegitan pelaporan rumah sakit masih menggunakan sistem manual yang cenderung memiliki risiko kesalahan data yang tinggi. Hal ini menjadi landasan kuat untuk merancang disain tampilan antarmuka sistem tersebut dan untuk melakukan hal itu diperlukan masukan berupa kebutuhan pengguna terhadap sistem yang dirancang. Tujuan: mengidentifikasi permasalahan sensus harian rawat inap dan pelaporan rumah sakit, harapan pengguna terhadap sistem yang dibangun dan kebutuhan data yang diperlukan.
\end{abstract}

Metode: jenis penelitian ini deskriptif rancangan studi kasus dengan wawancara, observasi dan studi dokumen.

Hasil: Masih terjadi kesalahan pengisian data pada lembar sensus yang dilakukan di bangsal, sehingga masih ada data yang tidak konsisten dalam satu nomor rekam medis. Para pengguna khususnya petugas sensus dan petugas pelaporan memerlukan tampilan antarmuka yang interaktif dan familiar seperti tampilan pada form manual sensus harian. Sedangkan informasi yang harus bisa ditampilkan adalah info identitas pasien, info pasien-masuk, info pasien-pulang, rekapitulasi bangsal dan indeks. Terkait kegiatan penyajian pelaporan, kebutuhan sistem juga harus mengakomodasi output data berupa tampilan Grafik Barber Johnson sebagai informasi efisiensi pelayanan.

Kesimpulan: agar terbangun sistem informasi yang bermanfaat, sangat penting ditekankan pada peran serta pengguna dalam proses pembuatannya. Dalam tahap ini akan teridentifikasi permasalahan utama yang dialami pengguna dalam melakukan pekerjaannya; sekaligus solusi yang bisa diberikan secara sistemik guna peningkatan kinerja petugas serta peningkatan pelayanan organisasi.

Kata kunci: analisis kebutuhan sistem, kebutuhan pengguna, antarmuka sensus harian

Background: One of the most important elements related to user needs in developing an information system is the design of the interface as a channel for information between the system and its users. RSU 'Aisyiyah Ponorogo has applied SIMRS for several years, but its implementation has not been comprehensive yet. In the daily inpatient census section and hospital reporting activities are still using a manual system that tends to have a high risk of data errors. This becomes a reason to design the interface of the system and its requires in the form of user requirements for the system that is designed. The main stage of building a system is analyzing user needs, specifically identifying the wishes of users who will always interact with the system at all times in supporting their works.

Objective: to identify problems in inpatient daily census and hospital reporting activities, users' expectations of the system being built and the data needs of users.

Methods: descriptive research with a case study approach. Techniques of data collection were interview, observation and documented study.

Results: the problem of inpatient census section and hospital reporting section is a data filing error on the census sheet in the ward, therefore there is inconsistent data in patient record. System users, especially census officers and reporting officers, need an interactive and familiar interface such as a display on the daily census manual form. While the information that must be displayed is info on patient identity, inpatient info, discharged patient info, ward and index recapitulation. In reporting presentation activities, system must also accommodate the output data in the form of Barber Johnson Graph as healthcare efficient informations.

Conclusion: in order to build a useful information system, it is very important to emphasize the participation of users in the developing process. In this stage, the main problems experienced by users in carrying out their work must be identified; as well as solutions that can be given systemically to improve staff performance and improve organizational services.

Keywords: analysis of system requirements, user needs, daily census interface design. 


\section{PENDAHULUAN}

Saat ini sarana pelayanan kesehatan, tak terkecuali rumah sakit, dituntut untuk menggunakan teknologi dalam setiap kegiatan yang dilakukan guna mendukung kinerja yang lebih cepat, tepat dan benar. Sistem Informasi Manajemen Rumah Sakit (SIMRS) sebagai teknologi dalam mengelola data di rumah sakit kian berkembang seiring tuntutan tersebut. Sebagaimana tercantum dalam Undang-undang No.44 tahun 2009 tentang Rumah Sakit disebutkan bahwa setiap rumah sakit wajib melakukan pencatatan dan pelaporan tentang semua kegiatan penyelenggaraan rumah sakit dalam bentuk SIMRS.

$\begin{array}{crr}\text { Implikasi } & \text { dari } & \text { maraknya } \\ \text { pengembangan } & \text { SIMRS ini jelas }\end{array}$
menimbulkan dampak sebagaimana yang diharapkan. Pengumpulan data kesehatan tidak lagi dalam bentuk manual. Rilisnya system pelaporan rumah sakit SIRS 2011 memudahkan rumah sakit untuk mengirim pelaporannya secara elektronik dan seragam kepada dinas kesehatan hingga tingkat pusat. Output olahan data rumah sakit dapat diambil kapan saja dan dilakukan dalam hitungan detik muncul pada dashboard di meja pimpinan, sebagai informasi bahan pengambilan keputusan.

Namun beberapa kasus penerapan SIMRS juga mengalami kegagalan. Yang sering terjadi adalah aplikasi yang dihasilkan tidak sesuai dengan kebutuhan pengguna, dimana sistem tidak mengakomodasi informasi yang diperlukan serta rumitnya pengguna memakai aplikasi hanya untuk mencari data. Selain itu pilihan teknologi yang dibangun juga terkadang mengalami kesalahan persepsi, bahwa tidak semua teknologi yang paling mutakhir itu pasti dapat menyelesaikan masalah. Memang aplikasi yang dibangun boleh jadi menggunakan teknologi paling mutakhir, tetapi malah tidak tepat guna. Problemproblem ini yang tidak sesuai harapan, tentunya menjadikan pengguna mengalami kekecewaan sehingga menolak untuk memakai sistem, kemudian akhirnya kembali ke cara lama. Menurut Cafasaro dalam O'Brien (2005) penyebab kegagalan dalam membangun sistem informasi diantaranya tidak ada dukungan manajemen, pemakai (enduser) yang tidak dilibatkan dan penggunaan kebutuhan perusahaan yang tidak jelas.

Tuntutan pelaporan disertai data yang updated serta tuntutan kebutuhan pelayanan, ikut "memaksa" rumah sakit untuk segera membangun system informasi yang terintegrasi dan mengakomodasi segala kebutuhan informasi di seluruh lini pelayanan rumah sakit. Tak terkecuali RSU 'Aisyiyah Ponorogo yang juga telah merintis penerapan SIMRS di awal tahun 2016 dan kini masih dalam tahap perkembangan berkelanjutan. Terkait kegiatan sensusharian, mereka mengalami permasalahan dalam olahan data. Menurut petugas di sana, problem yang terjadi adalah kesalahan dalam membaca nomor rekam medis, dan ini otomatis juga menjadi salah dalam menuliskannya, sehingga menyebabkan data-pasien tidak dapat ditemukan saat diperlukan. Selain itu, terkait data pelaporan rumah sakit, petugas menginginkan data pasien rawat inap dapat langsung diambil setiap saat diperlukan, tanpa harus menghitung manual terlebih dahulu. Menghitung dengan cara manual dianggap memakan waktu lebih lama dan tentu saja risiko terjadi kesalahan lebih besar.

Problem-problem tersebut sangat erat berkait dengan system informasi. Oleh karena itu, perlu dibangun system yang mengatur kemana arus informasi berjalan, system yang mengakomodasi keinginan pengguna. Guna membangun system yang demikian, dan menghindari kegagalan, maka sistem harus didisain dengan tepat. Menurut Saputra \& Purnama (2012) disain merupakan tahap melakukan pemikiran untuk mendapatkan cara terefektif dan efisien mengimplementasikan sistem dengan bantuan data yang didapatkan dalam tahap analisa. Dalam disain ini akan menghasilkan desain arsitektur sistem dan desain interface (antarmuka).

Salah satu subkegiatan pada tahap disain ini adalah analisis kebutuhan pengguna dengan melakukan identifikasi 
data dan informasi yang diperlukan pengguna system, terutama untuk merancang disain antarmuka sebagai tampilan komunikasi antara system dan pemakai. Dalam hal kegiatan sensus harian rawat inap dan pelaporan rumah sakit, hal ini akan menyangkut kegiatan identifikasi input data dari bagian pendaftaran pasien, serta output data berupa info pasien dalam bentuk statistik rumah sakit.

Tujuan penelitian ini adalah melakukan analisis kebutuhan pengguna sistem sensus harian rawat inap RSU 'Aisyiyah Ponorogo untuk merancang disain antarmuka, khususnya mengidentifikasi permasalahan dalam kegiatan sensus harian rawat inap, harapan pengguna terhadap sistem yang dibangun dan kebutuhan data yang diperlukan pengguna. Hal ini dimaksudkan agar aplikasi yang dirancang, khususnya melalui disain antarmuka system dapat memberikan informasi yang dibutuhkan penggunanya. Sehingga manfaatnya tidak hanya dirasakan bagi pemakai system tersebut, tetapi juga memberikan manfaat pengalaman bagi perancang system yang lain bahwa identifikasi kebutuhan pengguna merupakan tahap yang sangat penting dan instruktif dalam membangun sebuah system.

Organisasi rumah sakit, merupakan sebuah system yang mana komponen organisasi satu sama lain akan saling berkait. Demikian pula sebuah system informasi, yang melekat sebagai tatanan pendukung operasi dalam pengelolaan organisasi. Menurut Hutahaean (2015) system informasi adalah suatu system dalam suatu organisasi yang mempertemukan kebutuhan pengelola transaksi harian, mendukung operasi, bersifat menajerial dan kegiatan strategi dari suatu organisasi dan menyediakan laporan-laporan yang dibutuhkan. Sebagai jembatan komunikasi antara manusia dengan system, maka perlu dibangun satu komponen perangkat lunak yaitu antarmuka (interface).

Antarmuka (interface) adalah bagian dari sebuah komputer dan perangkat lunaknya yang dapat berinteraksi dengan manusia dengan cara dilihat, didengar, disentuh atau dengan cara yang lainnya yang dapat dipahami atau mengarahkan penggunanya (Galitz, 2007). Sedangkan menurut Saputra \& Purnama (2012) disain antarmuka adalah gambaran/tampilan bagaimana perangkat lunak berkomunikasi dalam dirinya sendiri, dengan sistem yang berinteroperasi dengannya dan dengan manusia yang menggunakannya. Tampilan ini dibuat untuk memudahkan programmer dalam menterjemahkan ke dalam bentuk bahasa pemrograman. Sebagai gerbang komunikasi dengan pemakai, antarmuka menjadi sangat penting mengingat pengguna akan menuntut system atau aplikasi yang dibangun dapat digunakan dengan mudah, tidak rumit, interaktif, informatif dan membantu hasil kerja lebih efektif dan efisien. Rancangan antarmuka bertujuan agar program atau aplikasi yang dihasilkan terlihat lebih menarik dan mudah dimengerti saat dioperasikan (Saputra \& Purnama, 2012). Oleh karena itu, disain tampilan antarmuka harus memenuhi kondisi tersebut yang hanya dapat diperoleh bila perancang disain mampu menggali keinginan penggunanya secara detail.

Menurut McLeod dan Schell (2008) salah satu langkah pengembangan sistem adalah mengidentifikasi kebutuhan pengguna. Pengambilan data dilakukan dengan mewawancarai pengguna untuk mendapatkan ide mengenai apa yang diminta dari sebuah system. Untuk menentukan apakah disain antarmuka yang dikembangkan dapat diterima pengguna atau tidak, maka pembuat disain harus mempresentasikan prototype system tersebut kepada para pengguna untuk mengetahui apakah prototype tersebut telah memberikan hasil yang memuaskan cocok dengan kebutuhan pengguna.

\section{METODE}

Penelitian ini merupakan penelitian deskriptif dengan pendekatan studi kasus. Objek penelitian adalah kegiatan sensus harian rawat inap hingga pelaporan rumah sakit dengan subjek 
sebanyak 11 orang terdiri atas 1 orang petugas pelaporan, 8 perawat bangsal, 1 orang petugas pendaftaran pasien dan 1 orang petugas teknis/IT rumah sakit. Teknik pengumpulan data menggunakan teknik wawancara, observasi dan studi dokumen. Adapun penelitian dilakukan di RSU 'Aisyiyah Ponorogo, Jawa Timur saat masih dalam proses menerapkan sistem informasi rumah sakit (Maret dan April 2017).

\section{HASIL DAN PEMBAHASAN}

Sistem sensus harian rawat inap yang dilakukan masih secara manual, meskipun RSU 'Aisyiyah Ponorogo sudah memakai SIMRS sejak 2016. Tidak ada antarmuka input data dalam sistem ini sehingga tidak dapat dikerjakan pengambilan data oleh petugas mengolah data untuk keperluan pelaporan rumah sakit. Petugas pelaporan atau dalam hal ini ia sebagai pengguna sistem, menganggap bahwa sistem tidak mendukung pekerjaan dalam kegiatan sensus harian maupun kegiatan pelaporan. Sensus harian merupakan perhitungan jumlah pasien pada waktu tertentu. Sensus Harian Rawat Inap (SHRI) menunjukkan jumlah pasien yang dirawat inap pada saat dilakukan penghitungan sensus, ditambah dengan jumlah pasien admisi setelah dilakukan sensus yang lalu dan pulang sebelum dilakukan sensus berikutnya (Sudra, 2010). Dalam pekerjaan sensus harian, petugas harus melakukan perhitungan dengan cermat mengingat sensus harian memberikan informasi perubahan jumlah pasien dalam hitungan jam. Kegiatan pelaporan juga demikian, mengolah data harus secermat mungkin, mengingat data pelaporan akan menjadi informasi yang diperlukan sebagai dasar pengambilan keputusan, baik dalam lingkup kebijakan internal maupun kebijakan eksternal.

Sensus harian rawat inap di RSU 'Aisyiyah Ponorogo dilakukan setiap 24 jam sekali (setiap hari) oleh perawat bangsal dengan menggunakan formulir kertas sebagai media pencatatan data. Responden menyatakan harapannya agar ke depan sensus yang dikerjakan rutin ini bisa dilakukan secara elektronis. Manfaat penggunaan sistem informasi adalah mampu menjamin kualitas informasi yang dihasilkan dan meningkatkan efisiensi operasional (Hakam, 2016). Dengan kata lain, suatu sistem yang dibangun harus memiliki daya guna (usability) yaitu sejauhmana suatu produk dapat digunakan oleh pengguna untuk mencapai tujuan mereka dengan efektif dan efisien (Firmansyah, 2016).

Data yang ditulis dalam lembar sensus terdiri atas data: pasien baru, pasien pindah ruang, pasien pindahan dan pasien meninggal lebih atau kurang dari 48 jam. Formulir sensus yang telah diisi oleh perawat di semua bangsal kemudian dikumpulkan kepada petugas pendaftaran di tempat penerimaan pasien. Lalu petugas pendaftaran melakukan pengecekan ulang terhadap isi formulir itu melalui sistem saat pasien melakukan admisi (pendaftaran rawat inap). Jika semua formulir sudah diteliti dan sudah sesuai, lalu formulir disetorkan kepada petugas pelaporan di bagian pengolahan data rumah sakit. Selanjutnya petugas pelaporan merekap data sensus dari seluruh bangsal dan kemudian data diolah untuk menghitung indikator pelayanan rumah sakit. Salah satu penyajian data dari indikator yang dibuat tersebut adalah Grafik Barber Johnson. Grafik ini digunakan untuk melakukan analisis dalam mengambil keputusan terkait dengan memonitor kegiatan pada waktu tertentu dengan membandingkan hasil kegiatan tahun sebelumnya, sehingga dari grafik ini akan terlihat peningkatan efisiensi pelayanan rumah sakit (Budi, 2011).

Hasil observasi tentang sensus harian ini dapat digambarkan melalui bagan alur pengolahan data sensus harian rawat inap berikut ini. 


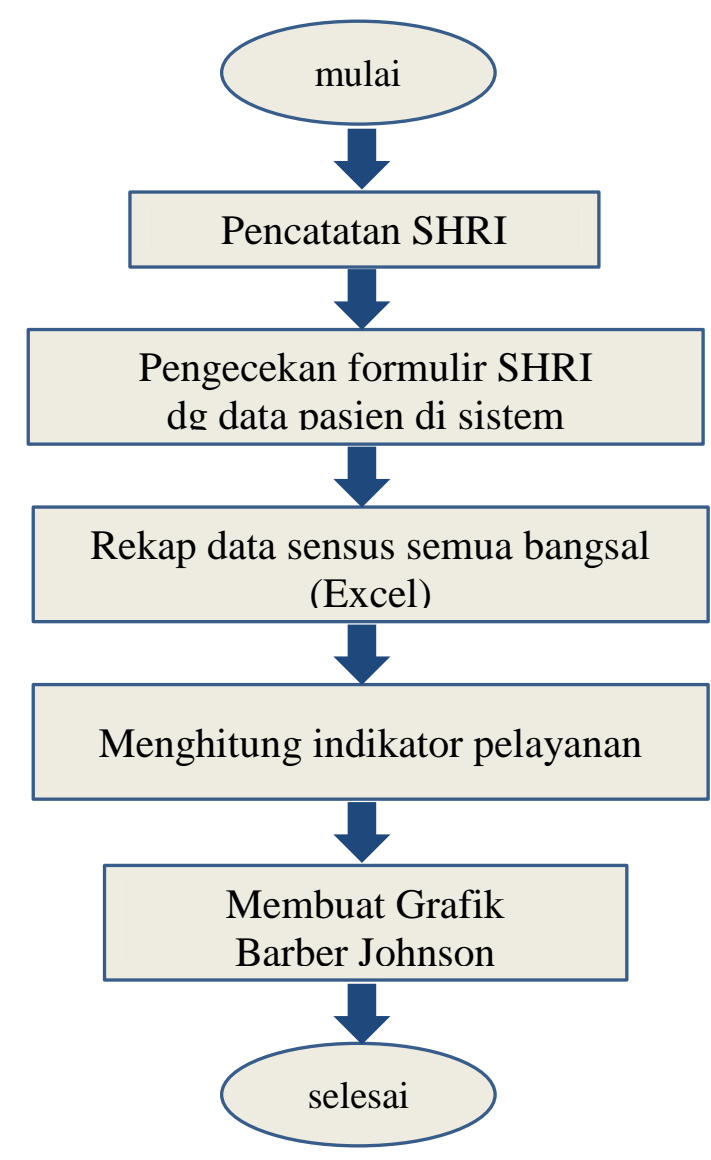

Gambar 1. Alur Sensus Harian Ranap

Alur pengumpulan data sensus harian rawat inap diperoleh dari hasil wawancara responden yang juga sebagai pengguna sistem. Pengguna yaitu pihakpihak yang akan bekerja dengan menggunakan aplikasi yang dibangun dalam system. Di sini yang dirancang adalah antarmuka untuk pengolahan sensus harian dan pengolahan data statistik rumah sakit. Di RSU 'Aisyiyah Ponotogo, pihak-pihak yang melaksanakan hal tersebut adalah petugas sensus harian rawat inap di bangsal, yaitu perawat bangsal dan petugas pelaporan yang mengolah data rumah sakit.

Dalam membangun sistem informasi, tahap awal yang dilakukan adalah melakukan analisis kebutuhan sistem, salah satu sumber data kegiatan ini adalah pengguna sistem yang justru sangat penting terlibat dalam perumusan kebutuhan sistem, mengingat mereka-lah yang akan menggunakan sistem bila sudah berjalan. Hal ini dilakukan mengingat salah satu prinsip dalam membangun sistem adalah sistem harus dapat digunakan oleh user, sehingga pengguna cepat dan mudah memahaminya. Menurut Nielsen dalam Firmansyah (2016) salah satu prinsip mengembangkan sistem adalah "Match between system and the real world" yaitu sistem harus sesuai dengan bahasa penggunanya, menggunakan kata, kalimat dan konsep yang biasa digunakan oleh pengguna. Oleh karena itu, dalam mendisain antarmuka, menurut Firmansyah (2016) harus memiliki karakteristik ragam dialog yang membari kemudahan untuk dikenal dengan mudah oleh penggunanya. Prinsip-prinsip dalam mengembangkan disain antarmuka diterapkan dengan cara pengambilan data dari para pengguna sistem. Langkah ini merupakan tahap analisis kebutuhan pengguna dalam membangun sistem yaitu mengidentifikasi klasifikasi user, analisis prosedur kerja, analisis dokumen, analisis peraturan serta identifikasi keinginan pemakai (Maniah \& Hamidin, 2017).

Selain itu, menurut Abdelhak \& Hanken (2012) salah satu prinsip umum disain adalah kebutuhan pengguna (need of user) yang mempertimbangkan kebutuhan pengguna dalam merancang disain antarmuka pengguna. Analisis kebutuhan sistem merupakan kegiatan untuk mengukur, mengetahui dan mengidentifikasi terkait kebutuhan dari model sistem yang dikembangkan, ini meliputi data yang akan diinput, proses dan output laporan, serta tampilan yang diinginkan pada sistem (Hakam, 2016). Berikut gambaran hasil analisis kebutuhan desain antarmuka pengguna.

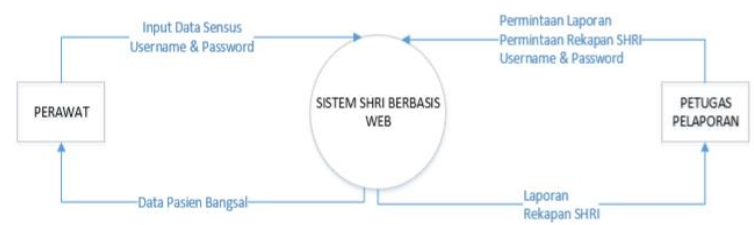

\section{Gambar 2. Diagram Konteks Sistem SHRI berbasis Web}

Diagram konteks perlu dibuat sebagai dasar menyusun Data Flow Diagram (DFD) sistem. DFD adalah alat untuk menggambarkan bagaimana suatu sistem berinteraksi dengan lingkungannya dalam bentuk data masuk ke dalam sistem 
dan keluar dari sistem (Sarosa, 2017). Hal ini juga didukung oleh Sulistyohati \& Hidayat (2008) bahwa DFD merupakan diagram aliran data yang menggambarkan bagaimana data diproses oleh sistem. Melalui DFD dapat digali apa saja yang dibutuhkan pengguna pada sistem yang dikembangkan. Secara garis besar data pada tahap ini adalah data yang sama dengan yang tertera di lembaran sensus harian rawat inap (manual) yaitu: identitas pasien yang pulang, kriteria pasien pulang (diijinkan pulang, pulang atas permintaan sendiri, rujukan, pasien meninggal, dan pasien pindah kelas), kategori pasien (BPJS, umum, asuransi lainnya). Merancang antarmuka sistem SHRI setidaknya menjawab harapan pengguna akan adanya sistem elektronik untuk menunjang kegiatan sensus harian rawat inap berbasis web.

Menu yang tampil diharapkan tidak jauh berbeda dengan komponenkomponen data yang tertera di formulir manual, yang terdiri atas data: nama pasien, jenis kelamin, umur, nomor rekam medis (NRM), tanggal masuk, tanggal keluar; data pasien keluar atau pulang dibuat kriteria: diijinkan pulang, atas permintaan sendiri, dirujuk, pasien meninggal; lalu nama DPJP, kategori pasien dan diagnosis. Kemudian diperlukan menu untuk input semua pasien yang pulang. Rancangan layar antarmuka yang baik adalah rancangan yang sesuai dengan kebutuhan pengguna (Mufti, 2015)

Menurut pengguna, permasalahan dalam sistem manual yang selama ini sering terjadi adalah salah baca nomor rekam medis pada lembar sensus oleh petugas pelaporan, sehingga data yang dimasukkan dengan excel (NRM pasien) salah. Masalah lain adalah pelaporan yang dobel/ganda yaitu data pasien pulang di suatu bangsal sudah dilaporkan dan dicatat sebagai pasien pulang hari itu, tetapi terjadi data yang sama dilaporkan lagi esok harinya, sehingga terdapat dua data yang sama. Artinya dalam dua hari dilaporkan satu data yang sama atau berulang. Sehingga apabila data sebulan direkap di akhir bulan, maka jumlah pasien pulang akan lebih banyak dari kenyataannya, atau dianggap bahwa jumlahnya tinggi/banyak. Harapan pengguna adalah dalam sistem yang baru tidak terjadi masalah-masalah tersebut di atas.

Hasil penelitian selanjutnya berdasarkan wawancara adalah data yang diperlukan pengguna. Data terkait kegiatan pelaporan yang diperlukan adalah info identitas pasien, info cara pulang pasien, info diagnosis, dan info bangsal ranap. Dalam integrasi system, salah satu kelebihan penggunaan system adalah efisiensi penangkapan data, sehingga seluruh data yang diperlukan harus terakomodasi pada system mengingat kepentingan SIMRS adalah untuk efisiensi data sehingga data harus akurat, tepat, dan cepat; sehingga dapat diketahui bahwa data yang diperlukan perawat bangsal sebagai petugas sensus harian rawat inap dalam antarmuka adalah sebagai berikut:

a. (Cari data) pasien dengan kata kunci NRM dan nama pasien;

b. (Input) data pasien-masuk;

c. (Input) data pasien-keluar;

d. Rekapitulasi data bangsal.

Sedangkan data yang diperlukan petugas pelaporan adalah sebagai berikut:

a. (Cari data) pasien dengan kata kunci NRM dan nama pasien;

b. Rekapitulasi pasien rawat inap;

c. Indikator pelayanan : bangsal, rumah sakit dan Grafik Barber Johnson;

d. Indeks.

SIMRS merupakan tatanan yang berurusan dengan pengumpulan data, pengolahan data, penyajian informasi, analisa dan penyimpulan informasi serta penyampaian informasi yang dibutuhkan untuk kegiatan rumah sakit (Hakam, 2016). Terkait perancangan desain antarmuka, analisis kebutuhan pengguna menghasilkan data yang diperlukan untuk merancang desain antarmuka yang sesuai dengan kebutuhan penggunanya.

Tampilan antarmuka pada kegiatan input pada sistem SHRI ini mengacu pada lembar sensus harian rawat inap. Menurut Depkes dalam Rustiyanto (2015) lembar ini harus berisi tentang data pasien 
masuk, pasien keluar, pasien dipindahkan, pasien pindahan, pasien meninggal 48 jam, meninggal 48 jam dihitung selama 24 jam dari pukul 00.00 sampai dengan 24.00. Sedangkan tampilan antarmuka pada kegiatan output kegiatan sensus harian rawat inap mengacu pada tampilan formulir RL 1.2 Indikator Pelayanan Rumah Sakit pada Juknis SIRS 2011. Pada formulir tersebut memuat nilai BOR, LOS, TOI, BTO, NDR, GDR, dan rata-rata kunjungan per hari di setiap tahun.

Adapun perwujudan desain antarmuka pada proses input dan proses output dapat dilihat pada tabel berikut ini.

Tabel 1. Perwujudan Desain Antarmuka Proses Input

\begin{tabular}{ll}
\hline \multicolumn{1}{c}{ USER } & \multicolumn{1}{c}{ INPUT } \\
\hline $\begin{array}{l}\text { Perawat, Petugas } \\
\text { Pelaporan }\end{array}$ & Log in \\
$\begin{array}{l}\text { Perawat, Petugas } \\
\text { Pelaporan }\end{array}$ & Cari pasien berdasar NRM \\
$\begin{array}{l}\text { Perawat, Petugas } \\
\text { Pelaporan }\end{array}$ & $\begin{array}{l}\text { Cari pasien berdasar nama } \\
\text { pasien }\end{array}$ \\
Perawat & Sub menu pasien masuk OB \\
Perawat & Sub menu pasien masuk \\
& pindahan \\
Perawat & Form pasien masuk OB \\
Perawat & Form pasien masuk pindahan \\
Perawat & Sub menu pasien keluar \\
& hidup \\
Perawat & Sub menu pasien meninggal \\
Perawat & Form pasien keluar hidup \\
Perawat & Form pasien keluar \\
& dipindahkan \\
Perawat & Form pasien keluar \\
& meninggal \\
\hline Total 12 tampilan & \\
\hline
\end{tabular}

Tabel 2. Perwujudan Desain Antarmuka Proses Output

\begin{tabular}{|c|c|}
\hline USER & OUTPUT \\
\hline $\begin{array}{l}\text { Perawat, Petugas } \\
\text { Pelaporan }\end{array}$ & Halaman utama \\
\hline $\begin{array}{l}\text { Perawat, Petugas } \\
\text { Pelaporan }\end{array}$ & Data pencarian pasien \\
\hline $\begin{array}{l}\text { Perawat, Petugas } \\
\text { Pelaporan }\end{array}$ & Data pencarian pasien \\
\hline Perawat & Daftar pasien masuk OB \\
\hline Perawat & Daftar pasien masuk pindahan \\
\hline $\begin{array}{l}\text { Perawat, Petugas } \\
\text { Pelaporan }\end{array}$ & Rekapitulasi pasien awal \\
\hline $\begin{array}{l}\text { Perawat, Petugas } \\
\text { Pelaporan }\end{array}$ & Rekapitulasi pasien masuk \\
\hline $\begin{array}{l}\text { Perawat, Petugas } \\
\text { Pelaporan }\end{array}$ & Rekapitulasi pasien pindahan \\
\hline
\end{tabular}

Tabel 2. (lanjutan) Perwujudan Desain Antarmuka Proses Output

\begin{tabular}{|c|c|}
\hline Perawat, Petugas & Rekapitulasi pasien keluar \\
\hline \multicolumn{2}{|l|}{ Pelaporan } \\
\hline Perawat, Petugas & Rekapitulasi pasien \\
\hline Pelaporan & dipindahkan \\
\hline Perawat, Petugas & Rekapitulasi pasien akhir \\
\hline \multicolumn{2}{|l|}{ Pelaporan } \\
\hline Perawat, Petugas & Rekapitulasi total \\
\hline \multicolumn{2}{|l|}{ Pelaporan } \\
\hline Petugas & Indikator bangsal \\
\hline \multicolumn{2}{|l|}{ Pelaporan } \\
\hline $\begin{array}{l}\text { Petugas } \\
\text { Pelaporan }\end{array}$ & Indikator rumah sakit \\
\hline Petugas & Indeks penyakit \\
\hline \multicolumn{2}{|l|}{ Pelaporan } \\
\hline Petugas & Indeks kematian \\
\hline \multicolumn{2}{|l|}{ Pelaporan } \\
\hline Petugas & Indeks cara pulang \\
\hline Pelaporan & \\
\hline Petugas & Indeks dokter \\
\hline Pelaporan & \\
\hline Total 18 tampilan & \\
\hline
\end{tabular}

Untuk merealisasikan desain tampilan antarmuka menjadi sebuah aplikasi, diperlukan tabel perwujudan sebagaimana tertera di atas. Perlu dipahami cara kerja sistem yang akan dibangun. Secara umum kerja sebuah sistem adalah menangkap atau menerima sebuah masukan (input) dan nantinya akan diolah menjadi keluaran (output) yang dapat dimanfaatkan berdasarkan tujuan sebuah sistem dan kaitan input dan output ini tak dapat dipisahkan (Hakam, 2016).

Selain memerlukan informasi tentang kebutuhkan terkait data input dan output sistem SHRI, dalam mendisain tampilan antarmuka juga diperlukan kebutuhan sistem terkait layout tampilan. Dalam penelitian ini penentuan layout tampilan disain antarmuka terdiri atas tata letak, warna, bentuk dan ukuran tulisan, diserahkan kepada pihak perancang. Para pemakai beranggapan bahwa setiap perancang harus berpegang pada prinsip disain grafis guna tampilan akhir antarmuka pemakai yang lebih menarik dan mudah digunakan. Sebagaimana hasil analisis kebutuhan pengguna dalam penelitian Saputra \& Purnama (2012) bahwa perangkat lunak harus dirancang menjadi mudah dan memiliki tampilan yang menarik bagi penggunanya. 
Demikian juga dengan hasil penelitian Sulistyohati \& Hidayat (2008) bahwa user sangat tertarik menggunakan sistem terutama disebabkan oleh karena tampilan antarmuka yang user friendly, pewarnaan bagus, serta informasi yang diberikan sistem sesuai kebutuhan user. Prinsip penting disain tampilan agar lebih menarik terkait disain grafis adalah layout. Layout berupa susunan beberapa elemen yang berbeda seperti tipografi, titik, garis dan bentuk (Arindiono \& Ramadhani, 2013). Untuk menyusun layout perlu dilakukan dengan teliti guna menentukan karakterisik (bentuk, ukuran, posisi) yang tepat dan menyatu sebagai sebuah tampilan.

Terkait unsur disain grafis, responden atau pengguna tidak berminat untuk terlibat menentukan. Sepanjang data yang mereka perlukan telah terakomodasi dalam sistem, maka unsur grafis merupakan pelengkap. Oleh karena itu, setelah disain tampilan berhasil dibuat, diadakan ujicoba dengan melakukan diskusi tentang produk yang dihasilkan. Tahap ujicoba merupakan penilaian terhadap sistem yang dibuat guna mengetahui apakah rancangan sudah sesuai dengan kebutuhannya (Hakam, 2016),

\section{PENUTUP}

Pelaksanaan sensus harian dan pengolahan data rumah sakit RSU 'Aisyiyah Ponorogo sangat memerlukan dukungan sistem informasi.

Pengembangan sistem tersebut diharapkan dapat mengatasi masalahmasalah yang dihadapi sistem manual yaitu kesalahan dalam penulisan nomor rekam medis, yang berakibat terjadi kesalahan data pasien. Selain itu juga masalah data ganda, yaitu pelaporan data dilakukan berulang sehingga terjadi banyak duplikasi data.

Hasil analisis kebutuhan pengguna terhadap data untuk merancang disain tampilan antarmuka kegiatan sensus harian rawat inap dan pelaporan rumah sakit adalah info pasien; input data pasien-masuk dan pasien-keluar; rekapitulasi data bangsal; indikator pelayanan rawat inap dan indeks data.
Dari simpulan tersebut di atas, maka direkomendasikan kepada pihak lapangan untuk mewujudkan sistem informasi rumah sakit terintegrasi dengan melibatkan pengguna secara simultan mulai dari proses analisis kebutuhan, mendisain, implementasi hingga evaluasi sistem.

\section{DAFTAR PUSTAKA}

Abdelhak, M., \& mary alice hanken. (2016). Health information: management of a strategic resource. In Health information: management of a strategic resource (p. 771). https://doi.org/10.1111/j.14390310.1995.tb00895.x

Arindiono, R. Y., \& Ramaadhani, N. (2013). Perancangan media pembelajaran interaktif matematika untuk siswa kelas 5 SD Rudi. Jurnal Sains Dan Seni Pomits, 2(1), 28-32.

Budi, S. C. (2013). Manajemen Unit Kerja Rekam Medis. Yogyakarta: Quantum Sinergis Media.

Firmansyah, R. (2016). Evaluasi Heuristik pada Desain Interface Aplikasi My Indihome. In Seminar Nasional Ilmu Pengetahuan dan Teknologi Komputer Nusa Mandiri. SNIPTEK 2016.

Galitz, W. O. (2007). The Essential Guide to Interface Design: An Introduction to GUI Design Principles and Techniques. Indiana: Willey Publishing.

Hakam, F. (2016). Analisis, Perancangan dan Evaluasi Sistem Informasi Kesehatan. Yogyakarta: Gosyen Publishing.

Hutahaean, J. (2015). Konsep Sistem Informasi. Yogyakarta: Deepublish.

Maniah \& Dini Hamidin. (2017). Analisis dan Perancangan System Informasi. In Pembahasan Secara Praktis dengan Contoh Kasus. Yogyakarta: Deepublish.

McLeod, R. J. \& G. S. (2008). Management Information System (10th ed). Jakarta: Salemba Empat.

Mufti, A. (2015). Rancangan Layar sebagai Alat Bantu Pendewasa Interaksi Manusia dengan Komputer. Jurnal Faktor Exacta, Volume 8(No 2). 
O'Brien, J. A. (2005). Introduction to Information Systems. In Essentials for The Internetworked E-bussiness Enterprise. McGraw Hills.

Rustiyanto, E. (2015). Statistik Rumah Sakit untuk Pengambilan Keputusan. Yogyakarta: Graha Ilmu.

Saputra, W. \& B. E. P. (2012). Pengembangan Multimedia Penbelajaran Interaktif untuk Mata Kuliah Organisasi Komputer. Jurnal Speed - Sentra Penelitian Engineering
Dan Edukasi, Volume 4(No. 2).

Sudra, R. I. (2010). Statistik Rumah Sakit. In sensus pasien dan Grafik Barber Jhonson hingga statistik kematian dan otopsi. Yogyakarta: Graha Ilmu.

Sulistyohati, A. dan T. H. (2008). Aplikasi Sistem Pakar Diagnosa Penyakit Ginjal dengan Metode DempsterShafer. In Seminar Nasional Aplikasi Teknologi Informasi 2008. 